\title{
COMPARISON OF OSTEOARTHRITIS HERBAL EXTRACT VERSUS MELOXICAM IN REDUCING PAIN IN PATIENTS WITH KNEE OSTEOARTHRITIS: A RANDOMIZED CONTROLLED TRIAL
}

\author{
Danang Ardiyanto, Saryanto, Fajar Novianto, Zuraida Zulkarnain
}

Center for Research and Development of Medicinal Plants and Traditional Medicines, Health Research and Development Agency, Ministry of Health, Indonesia

\begin{abstract}
Background: Abnormalities of the joints, associated muscles, tendons, ligaments and bone structural abnormalities can all result in pain and need for neurosurgical consultations. Typically, patients will not require immediate surgical intervention, and therefore require treatments to reduce pain and enhance quality of life activities. The purpose of this study was to compare the effect of osteoarthritis herbal extract versus meloxicam in reducing pain in patients with knee osteoarthritis.

Subjects and Method: A randomized controlled trial was conducted at House of Herbs Research Tawangmangu, Karanganyar, Central Java, from March to October 2019. A number of 80 knee OA patients was divided into two groups, (1) OA herbal extract capsules and (2) meloxicam. The dependent variable was pain. The independent variables were OA herbal extract capsules and meloxicam. OA herbal extract capsules consist of Curcuma xanthorrhiza, Phyllanthus niruri, Curcuma longa, Foeniculum vulgare, Orthosiphon aristatus, Centella asiatica, and Equisetum debile. Pain was measured by visual analogue scale. Intervention was carried out for 4 weeks (28 days). Pain was measured 3 times, (1) before intervention, (2) second week (day-14), and (3) fourth week (day-28). Pain level after 28 days between OA herbal extract capsules and meloxicam groups was analyzed using independent t-test.

Results: Most of the study subjects was female (80\%). Mean of age was 57 years $($ Mean $=57.45)$. After 28 days, there was no difference of pain between osteoarthritis herbal extract capsules group $(\mathrm{Mean}=53.50 ; \mathrm{SD}=4.41)$ and meloxicam group (Mean= 53.88; $\mathrm{SD}=9.64$ ), with $\mathrm{p}=0.824$.
\end{abstract}

Conclusion: There is no difference of pain between osteoarthritis herbal extract capsules group and meloxicam group

Keywords: osteoarthritis, herbal, meloxicam, visual analogue scale

\section{Correspondence:}

Danang Ardiyanto. Center for Research and Development of Medicinal Plants and Traditional Medicines, Health Research and Development Agency, Ministry of Health, Indonesia. Jl. Raya Lawu 11 Tawangmangu, Karanganyar, Central Java. Email: drdanank@gmail.com. Mobile: 08122762579. 